\title{
Hubungan Paritas, Biaya dan Pendidikan dengan KB Implant
}

\author{
Nuraini", Siti Aisyah, Putu Lusita Nati Indriani \\ Program Studi DIV Kebidanan Fakultas Kebidanan dan Keperawatan, Universitas Kader Bangsa Palembang \\ *Correspondence email: ainilubukbuah@gmail.com
}

\begin{abstract}
Abstrak. Keluarga Berencana (KB) adalah tindakan yang membentuk individu atau pasangan suami istri untuk mendapatkan objektif-objektif tertentu. Tujuan penelitian ini Untuk mengetahui hubungan paritas, biaya dan pendidikan dengan KB implant. Jenis penelitian ini kuantitatif menggunakan survey analitik dengan pendekatan studi Cross Sectional untuk melihat hubungan sesaat antara variabel independen dan dependen. Sample pada pada penelitian ini adalah seluruh dari wanita usia subur yang merupakan peserta KB aktif. Waktu pengumpulan data dalam penelitian ini dilakukan pada tanggal 12 Februari 2020, dan proses pengambilan data dilakukan pada 25 Juni sampai 18 Agustus 2020, uji statistik dengan menggunakan Uji Chi-Square. Hasil penelitian responden yang tidak menggunakan KB Implant sebanyak (57,9\%), Responden yang paritasnya beresiko sebanyak $(32,6 \%)$, Responden yang biaya pemasangan KB Implant secara mandiri sebanyak $(60,0 \%)$ dan yang biaya pemasangan KB Implant menggunakan BPJS sebanyak (40,0\%). Sedangkan responden yang pendidikannya rendah sebanyak (40\%). Hasil uji statistik diketahui tidak ada hubungan yang signifikan antara paritas ( $p$-value $=0,363)$, ada hubungan biaya $(p$-value $=0,003)$, dan pendidikan $(p$-value $=0,000)$. Saran diharapkan agar tim kesehatan yang ada di pelayanan masyarakat lebih aktif memberikan pelatihan bagi ahli kebidanan yang berhubungan dengan Akseptor KB Implant.
\end{abstract}

Kata kunci: Implant; Paritas; Biaya dan Pendidikan

Abstract. Family planning (KB) is an act that shapes an individual or a married couple to get certain objectives. Objective: To determine the relationship between parity, cost and education with implant family planning. This type of research is quantitative using an analytic survey with a cross sectional study approach to see the momentary relationship between the independent and dependent variables. The samples in this study were all women of childbearing age who were active family planning participants. The time of data collection in this study was carried out on February 12,2020, and the data collection process was carried out on June 25 to August 18, 2020, statistical tests using the Chi-Square Test. The results of the research of respondents who did not use implant family planning (57.9\%), respondents whose parity was at risk as much as (32.6\%), respondents who had the cost of implanting FP implants independently were (60.0\%) and those who were Implant using BPJS as much (40.0\%). Meanwhile, respondents with low education were $(40 \%)$. The statistical test results show that there is no significant relationship between parity $(p$-value $=0.363)$, there is a relationship between costs $(p$-value $=0.003)$, and education $(p$-value $=0.000)$. It is hoped that the health team in community services will be more active in providing training for obstetricians who are related to family planning implant acceptors.

Keywords: Implant; Parity; Cost and Education

\section{PENDAHULUAN}

Menurut Word Health Organization (WHO) keluarga Berencana adalah tindakan yang membentuk individu atau pasangan suami istri untuk mendapatkan objektif-objektif tertentu. Menghindari kelahiran yang tidak diinginkan, mendapatkan kelahiran yang memang diinginkan, mengatur interval diantara kehamilan, mengontrol waktu saat kelahiran, menentukan jumlah anak dalam keluarga (Sulistyawati, 2011).

Hidayah dan Harahap (2016) Data dalam Survei Demografi dan Kesehatan Indonesia (SDKI) memperlihatkan kemajuan - kemajuan yang dicapai program keluarga berencana (KB) dalam 5 tahun terakhir dan kontribusinya terhadap situasi transisi demografi di Indonesia. Total Fertility Rate (TFR) Indonesia mengalami penurunan sebanyak 0,2 poin dari 2,6 perwanita usia subur. Pada SDKI tahun 2012 menjadi 2,4 perwanita usia subur .

Indonesia merupakan Negara yang dilihat dari jumlah penduduknya ada pada posisi ke 4 didunia, dengan laju pertumbuhan yang masih relatif tinggi, esensi Tugas Program Keluarga Berencana (KB) dalam hal ini telah jelas yaitu menurunkan fertilitas agar dapat mengurangi beban pembangunan demi terwujudnya kebahagiaan dan kesejahteraan bagi rakyat dan bangsa Indonesia. KB yakni supaya meningkatkan kepedulian dan peran serta masyarakat melalui pendewasaan usia perkawinan, pengaturan kelahiran, pembinaan ketahanan keluarga, dan peningkatan kesejahteraan keluarga guna mewujudkan keluarga kecil, bahagia dan sejahtera (Kusumaningrum, 2009).

Berdasarkan penelitian Marlina (2016) menunjukkan bahwa biaya menunjukkan kemampuannya berkaitan dengan kondisi sosial ekonomi dimana hasil penelitian menunjukkan bahwa proporsi akseptor yang merasa tidak mampu lebih banyak $(68,1 \%)$ dibandingkan dengan akseptor KB yang merasa mampu dengan biaya penggunaan implan $(31,9 \%)$. 


\section{METODE}

Penelitian ini menggunakan jenis penelitian survey analitik yang bersifat kuantitatif dimana variable independent paritas, biaya dan pendidikan dan variable dependen KB Implant dikumpulkan dalam waktu yang bersamaan (Notoatmodjo, 2010) dengan pendekatan cross sectional, yang bertujuan untuk mengetahui hubungan variabel independen yaitu paritas, biaya dan pendidikan dengan variabel dependen yaitu KB Implant.

Pengumpulan data dilakukan pada tanggal 12 Februari 2020, dan proses pengambilan data dilakukan pada 25 Juni sampai 18 Agustus 2020. Penelitian ini telah dilakukan di wilayah kerja Puskesmas Kabupaten Musi Banyuasin tahun 2020. Populasi dalam penelitian ini adalah semua wanita usia subur yang merupakan peserta KB aktif yang berkunjung di Puskesmas berjumlah 1.834 orang. Sampel dalah wanita usia subur yang merupakan peserta KB aktif. Besar sampel dalam penelitian ini dengan menggunakan rumus Notoatmodjo (2011):

$$
\begin{aligned}
& n=\frac{N}{1+N\left(d^{2}\right)} \\
& n=\frac{N}{1+N\left(d^{2}\right)} \\
& n=\frac{1834}{1+1834\left(0,1^{2}\right)} \\
& n=\frac{1834}{19,34} \\
& n=95
\end{aligned}
$$

Dengan menggunakan rumus di atas berdasarkan tingkat kepercayaan 0,1 (90\%) diperoleh sampel 96 orang, Sampel penelitian diambil menggunakan matode random sampling atau pengambilan sample secara acak sistematis dengan cara membagi jumlah sample yang diinginkan.

Tehnik pengolahan data setelah data terkumpul secara manual kemudian di olah dengan menggunakan komputer melalui beberapa tahap antara lain; editing, coding, entri, dan cleaning. Analisis data menggunakan analisis univariat dan analisis bivariat.
Adapun analisa yang dilakukan terhadap penelitian ini yaitu dengan menggunakan analisa data secara univariat yaitu untuk mengetahui distribusi frekuensi, kemudian analisa bivariat untuk mengetahui hubungan variabel dengan menggunakan Uji Chi-Square test.

Masalah etik penelitian merupakan masalah yang sangat penting dalam penelitian, mengingat penelitian kebidanan berhubungan langsung dengan manusia, maka segi etika penelitian harus diperhatikan. Masalah etika yang harus diperhatikan antara lain adalah; informed consent, anominity, dan confidentially (Handayani, 2018).

\section{HASIL DAN PEMBAHASAN}

\section{Analisis Univariat}

Analisis univariat ini dilakukan untuk mengetahui distribusi frekuensi dan presentase dari variabel dependen (Akseptor KB Implant) dan variabel independen (Paritas, Biaya dan Pendidikan) data disajikan dalam bentuk tabel dan teks.

Tabel 1. Distribusi frekuensi responden berdasarkan Karakteristik

\begin{tabular}{cllcc}
\hline No & & Variabel & Frekuensi & \% \\
\hline 1 & Akseptor KB & Ya & 40 & 42,1 \\
& Implant & Tidak & 55 & 57,9 \\
2 & Paritas & Tidak beresiko & 64 & 67,4 \\
& & Beresiko & 31 & 32,6 \\
3 & \multirow{2}{*}{ Biaya } & BPJS & 38 & 40 \\
& & Mandiri & 57 & 60 \\
4. & \multirow{2}{*}{ Pendidikan } & Tinggi & 57 & 60 \\
& & Rendah & 38 & 40 \\
\hline
\end{tabular}

Sumber: Data diolah

Pada tabel diatas dapat dilihat bahwa sebagian besar responden dengan tidak menggunakan $\mathrm{KB}$ implant $(32,6 \%)$, paritas yang beresiko $(32,6 \%)$, biaya secara mandiri $(60 \%)$ dan yang pendidikan rendah $(40 \%)$.

\section{Analisa Bivariat}

Analisa ini bertujuan untuk mengetahui hubungan

\begin{tabular}{|c|c|c|c|c|c|c|c|c|}
\hline \multirow{3}{*}{ Paritas } & \multicolumn{4}{|c|}{ Akseptor KB Implant } & \multirow{2}{*}{\multicolumn{2}{|c|}{ Jumlah }} & \multirow{2}{*}{ p-value } & \multirow{2}{*}{$\begin{array}{c}\text { OR } \\
95 \% C I\end{array}$} \\
\hline & \multicolumn{2}{|c|}{$\mathrm{Ya}$} & \multicolumn{2}{|c|}{ Tidak } & & & & \\
\hline & $\mathrm{n}$ & $\%$ & $\mathrm{n}$ & $\%$ & $\mathrm{~N}$ & $\%$ & \multirow{4}{*}{0,363} & \multirow{4}{*}{$\begin{array}{c}0,22 \\
(, 062-, 834)\end{array}$} \\
\hline Tidak beresiko & 29 & 45,3 & 35 & 54,7 & 64 & 100,0 & & \\
\hline Beresiko & 11 & 35,5 & 20 & 64,5 & 31 & 100,0 & & \\
\hline Jumlah & 40 & & 55 & & 95 & & & \\
\hline
\end{tabular}
secara simultan dan parsial antara variabel independen (paritas, biaya, dan pendidikan), dengan variabel dependen (akseptor KB Implant).

Tabel 2. Hubungan Paritas dengan Akseptor KB Implant

Sumber: Data diolah

Pada tabel di atas, terlihat bahwa responden yang jumlah anaknya $\geq 2$ orang yang menggunakan $\mathrm{KB}$
Implant sebanyak 11 orang $(35,5 \%)$ dan yang tidak menggunakan KB Implant sebanyak 20 orang $(64,5 \%)$. 
Hasil uji Chi-Square diperoleh nilai $p$ value 0,363 $(>\alpha=0,05)$, artinya tidak ada hubungan yang bermakna antara paritas dengan Akseptor KB Implant. Dari analisa didapat nilai OR 1,50 yang berarti responden yang paritasnya beresiko mempunyai peluang 1,5 kali dibandingkan dengan responden yang paritasnya tidak beresiko untuk menggunakan kontrasepsi Implant.

Tabel 3. Hubungan Biaya dengan Akseptor KB Implant

\begin{tabular}{|c|c|c|c|c|c|c|c|c|}
\hline \multirow{3}{*}{ Biaya } & \multicolumn{4}{|c|}{ Akseptor KB Implant } & \multirow{2}{*}{\multicolumn{2}{|c|}{ Jumlah }} & \multirow[b]{2}{*}{ p-value } & \multirow{2}{*}{$\begin{array}{c}\text { OR } \\
95 \% \mathrm{CI}\end{array}$} \\
\hline & \multicolumn{2}{|c|}{$\mathrm{Ya}$} & \multicolumn{2}{|c|}{ Tidak } & & & & \\
\hline & $\mathrm{n}$ & $\%$ & $\mathrm{n}$ & $\%$ & $\mathrm{~N}$ & $\%$ & \multirow{4}{*}{0,003} & \multirow{4}{*}{$3.608(1.522-8.553)$} \\
\hline BPJS & 23 & 60,5 & 15 & 39,5 & 38 & 100,0 & & \\
\hline Mandiri & 17 & 29,8 & 40 & 70,2 & 57 & 100,0 & & \\
\hline Jumlah & 40 & & 55 & & 95 & & & \\
\hline
\end{tabular}

Sumber: Data diolah

Pada tabel di atas terlihat bahwa responden yang menggunakan biaya mandiri yang menggunakan KB Implant sebanyak 17 orang $(29,8 \%)$ dan yang tidak menggunakan KB Implant sebanyak 40 orang $(70,2 \%)$.

Hasil uji Chi-Square diperoleh nilai $p$-value $0,003<0,05$, berarti ada hubungan yang bermakna antara biaya dengan Akseptor KB Implant. Dari analisa didapat nilai OR 3,60 bahwa responden yang biaya menggunakan biaya Mandiri atau yang mengangap KB implant itu mahal mempunyai peluang 3,6 kali dibandingkan dengan responden yang biayanya menggunakan BPJS untuk menggunakan kontrasepsi Implant.

Tabel 4. Hubungan Pendidikan dengan Akseptor KB Implant

\begin{tabular}{|c|c|c|c|c|c|c|c|c|}
\hline \multirow{3}{*}{ Pendidikan } & \multicolumn{4}{|c|}{ Kejadian Scabies } & \multirow{2}{*}{\multicolumn{2}{|c|}{ Jumlah }} & \multirow[b]{2}{*}{ p-value } & \multirow{2}{*}{$\begin{array}{c}\text { OR } \\
95 \% \mathrm{CI}\end{array}$} \\
\hline & \multicolumn{2}{|c|}{$\mathrm{Ya}$} & \multicolumn{2}{|c|}{ Tidak } & & & & \\
\hline & $\mathrm{n}$ & $\%$ & $\mathrm{n}$ & $\%$ & $\mathrm{~N}$ & $\%$ & \multirow{4}{*}{0,000} & \multirow{4}{*}{$\begin{array}{c}10.50 \\
(3.5-30.9)\end{array}$} \\
\hline Tinggi & 35 & 61,4 & 22 & 38,6 & 57 & 100,0 & & \\
\hline Rendah & 5 & 13,2 & 33 & 86,8 & 38 & 100,0 & & \\
\hline Jumlah & 40 & & 55 & & 95 & & & \\
\hline
\end{tabular}

Sumber: Data diolah

Pada tabel di atas terlihat bahwa responden yang pendidikannya < SMA yang menggunakan KB Implant sebanyak 5 orang $(13,2 \%)$ dan yang tidak menggunakan KB Implant sebanyak 33 orang $(86,8 \%)$.

Hasil uji Chi-Square diperoleh nilai p-value $0,000<0,05$, berarti ada hubungan yang bermakna antara pendidikan dengan Akseptor KB Implant.

Dari analisa didapat nilai OR 10,500 bahwa responden yang pendidikannya rendah mempunyai peluang 10,5 kali dibandingkan dengan responden yang pendidikannya tinggi untuk menggunakan kontrasepsi Implant.

\section{Pembahasan}

\section{Hubungan Paritas dengan Akseptor KB Implant}

Berdasarkan hasil penelitian yang telah dilakukan, dapat dilihat bahwa wanita yang jumlah anak < dari 2 orang sebanyak 64 orang $(67,4 \%)$, lebih besar dari pada wanita jumlah anak $\geq 2$ orang sebanyak 31 orang $(32,6$ $\%)$.

Hasil uji Chi-Square diperoleh nilai $p$ value $0,363<0,05$, berarti tidak ada hubungan yang bermakna antara paritas degan akseptor KB Implant. Dari analisa didapat nilai OR 1.506 artinya responden yang paritasnya beresiko mempunyai peluang 1,5 kali dibandingkan dengan responden yang paritasnya tidak beresiko untuk menggunakan kontrasepsi Implant.
Paritas adalah keadaan wanita yang berhubungan jumlah anak yang dilahirkan ibu. Presentase paritas yang memakai metode kontrasepsi implant adalah 58,8 \% pada ibu dengan pritas tinggi dan $42,2 \%$ pada ibu dengan paritas rendah sehingga disimpulkan bahwa ibu yang paritas tinggi (anak $\geq 3$ orang) lebih banyak menggunakan metode kontrasepsi implant dibandingkan ibu paritas rendah (anak <3 orang) (Manuaba, 2011).

Sejalan dengan penelitian yang dilakukan Firdausi (2015), bahwa dari variabel paritas dengan kelompok yang memakai implant 30,95\% memiliki anak >2 dan 29,49\% pada kelompok yang tidak memakai Implant.

Sejalan dengan penelitian yang dilakukan Daulay (2020) bahwa terdapat hubungan faktor paritas dengan rendahnya penggunaan $\mathrm{KB}$ implant pada wanita usia subur sebesar $35 \%$.

Peneliti menyimpulkan bahwa bahwa ibu yang paritas tinggi / beresiko (anak > 2 orang) lebih sedikit menggunakan metode kontrasepsi implant dibandingkan ibu paritas rendah / tidak beresiko (anak $\leq 2$ orang).

\section{Hubungan Biaya dengan Akseptor KB Implant}

Berdasarkan dari hasil tabel diatas, maka responden yang menggunakan BPJS atau asuransi lain sebanyak 38 orang $(40,0 \%)$, lebih kecil dari pada responden yang menggunakan biaya sendiri sebanyak 57 orang $(60,0 \%)$. 
Hasil uji Chi-Square diperoleh nilai p-value $0,003<0,05$, berarti ada hubungan yang bermakna antara biaya dengan Akseptor KB Implant. Dari analisa didapat nilai OR 3.608 artinya responden yang biaya menggunakan biaya Mandiri atau yang mengangap KB implant itu mahal mempunyai peluang 3,6 kali dibandingkan dengan responden yang biayanya menggunakan BPJS untuk menggunakan kontrasepsi Implant.

Biaya dapat mempengaruhi jangkauan pemakaian kontrasepsi pada akseptor KB. Hasil uji regresi logistik, dapat diketahui bahwa biaya pemakaian kontrasepsi berpengaruh signifikan terhadap pemilihan metode kontrasepsi. Akseptor KB yang menganggap biaya yang harus ditanggung untuk mendapatkan pelayanan kontrasepsi tidak mahal, mempunyai kemungkinan 0,078 kali lebih besar untuk memilih kontrasepsi non MKJP (Metode Kontrasepsi Jangka Panjang) dibandingkan yang harus ditanggung untuk mendapatkan pelayanan kontrasepsi mahal.

Marlina (2016) menunjukkan bahwa biaya menunjukkan kemampuannya berkaitan dengan kondisi sosial ekonomi dimana hasil penelitian menunjukkan bahwa proporsi akseptor yang merasa tidak mampu lebih banyak $(68,1 \%)$ dibandingkan dengan akseptor KB yang merasa mampu dengan biaya penggunaan implan $(31,9 \%)$.

Peneliti menyimpulkan bahwa memang benar ada keterkaitan antara biaya dengan pemakaian kontrasepsi KB Implant. Lebih banyak responden yang menggunakan pembiayaan BPJS untuk menggunakan KB implant daripada menggunakan biaya mandiri.

\section{Hubungan Pendidikan dengan Akseptor KB Implant}

Berdasarkan dari hasil tabel diatas, maka responden yang pendidikannya tinggi sebanyak 57 orang (60 \%), lebih besar dari pada responden yang pendidikanya rendah sebanyak 38 orang $(40 \%)$.

Pada tabel terlihat bahwa proporsi responden yang pendidikannya < SMA yang menggunakan KB Implant sebanyak 5 orang $(13,2 \%)$ dan yang tidak menggunakan KB Implant sebanyak 33 orang $(86,8 \%)$.

Hasil uji Chi-Square diperoleh nilai $p$-value $0,000<0,05$, berarti ada hubungan yang bermakna antara pendidikan dengan Akseptor KB Implant. Dari analisa didapat nilai OR 10.500 artinya responden yang pendidikannya rendah mempunyai peluang 10,5 kali dibandingkan dengan responden yang pendidikannya tinggi untuk menggunakan kontrasepsi Implant.

Peran pendidikan dalam mempengaruhi pola pemikiran wanita untuk menentukan kontrasepsi mana yang lebih sesuai untuk dirinya, kecenderungan ini menghubungkan antara tingkat pendidikan akan mempengaruhi pemahaman dan pengetahuan seseorang, berdasarkan penelitian di Cambodia menegaskan tentang hubungan pendidikan dengan pemilihan kontrasepsi modern sangat berkaitan (Gross et al, 2010).
Peneliti menyimpulkan bahwa memang benar ada keterkaitan antara tingkat pendidikan seorang wanita untuk menentukan kontrasepsi yang akan digunakan. Dengan tingginya pendidikan seseorang berarti pengetahuan yang dimilikinya lebih banyak.

\section{SIMPULAN}

1. Ada hubungan antara Paritas, Biaya dan Pendidikan secara simultan dengan Akseptor KB Implant

2. Tidak Ada hubungan yang bermakna Paritas secara parsial dengan Akseptor KB Implant ( $p$-value $=$ 0,363 )

3. Ada hubungan yang bermakna biaya secara parsial dengan Akseptor KB Implant ( $p$-value $=0,003$ )

4. Ada hubungan yang bermakna Pendidikan secara parsial dengan Akseptor $\mathrm{KB}$ Implant ( $p$-value $=$ $0,000)$

\section{DAFTAR PUSTAKA}

Daulay, S. A. (2020). Faktor yang Berhubungan Dengan Rendahnya Penggunaan KB Implant Pada Wanita Pasangan Usia Subur (WUS) di Desa Pintupadang Kecamatan Batang Angkola Tahun 2020. Jurnal Kesehatan Ilmiah Indonesia (Indonesian Health Scientific Journal), 5(2), 27-35.

Gross, K. A., Saber-Samandari, S., \& Heemann, K. S. (2010). Evaluation of commercial implants with nanoindentation defines future development needs for hydroxyapatite coatings. Journal of Biomedical Materials Research Part B: Applied Biomaterials: An Official Journal of The Society for Biomaterials, The Japanese Society for Biomaterials, and The Australian Society for Biomaterials and the Korean Society for Biomaterials, 93(1), 1-8.

Handayani, L. T. (2018). Kajian Etik Penelitian Dalam Bidang Kesehatan Dengan Melibatkan Manusia Sebagai Subyek. The Indonesian Journal of Health Science, 10(1).

Hidayah, A., \& Harahap, Y. V. (2016). FAKTORFAKTOR YANG MEMPENGARUHI RENDAHNYA PENGUNAAN KB IMPLANT PADA WANITA USIA SUBUR (WUS) DI DESA PARTIHAMAN SAROHA KECAMATAN PADANG SIDIMPUAN HUTAIMBARU TAHUN 2016. Jurnal Kesehatan Ilmiah Indonesia (Indonesian Health Scientific Journal), 1(3), 4755.

Kusumaningrum, R. (2009). Faktor-faktor yang mempengaruhi pemilihan jenis kontrasepsi yang digunakan pada pasangan usia subur. Universitas Diponegoro, 1-59.

Manuaba, I. B. G. (2011). Ilmu Kebidanan, Dan Keluarga Berencana Untuk Pendidikan Bidan. Jakarta: $E C G$.

Marlina. 2016. Analisis Faktor Yang Berhubungan Dengan Penggunaan Implant oleh Akseptor KB di 
Puskesmas Rawat Inap Sukabumi Kota Bandar Lampung.

Notoatmodjo, S. (2010). Promosi Kesehatan Teori \& Perilaku. Jakarta: Rineka Cipta, 275.

Notoatmodjo, S. (2011). Kesehatan masyarakat ilmu dan seni.

Nuzula, Firdausi. 2015. Faktor - factor yang Berhubungan Dengan Pemakaian Implant pada Wanita Pasangan Usia Subur di Kecamatan Tegal Sari Kabupaten Banyuwangi.

Sulistyawati, Ari. 2011. Pelayanan KB. Jakarta Selatan : Salemba Medika. 